\title{
Variation and Pattern in the 3-term Syllogisms and the Biliteral Sorites of Types Barbara, Darapti and Darii
}

To the memory of my sister Cristina Popa, 1948-2018.

\author{
DAN CONSTANTIN RADULESCU ${ }^{[0000-0002-0648-8794]}$ \\ Retired, Boynton Beach FL 33435, USA \\ dancradulesculyahoo.com, schugu.com
}

\begin{abstract}
In both Classical Syllogistics and the biliteral sorites of Barbara, Darapti and Darii types, it is worth to examine only the fundamental patterns. Instead of writing the general premises of a Barbara type sorite as $\mathrm{M}_{1}{ }^{*} \subseteq \mathrm{M}_{2}{ }^{*} \subseteq \mathrm{M}_{3}{ }^{*} \subseteq \ldots \subseteq \mathrm{M}_{\mathrm{n}}{ }^{*}$, where $\mathrm{M}_{\mathrm{i}}{ }^{*} \in\left\{\mathrm{M}_{\mathrm{i}}, \mathrm{M}_{\mathrm{i}}{ }^{\prime}\right\}, \mathrm{i}=1,2, \ldots, \mathrm{n}$, and examining $2^{\mathrm{n}}$ possible Barbara sorites, one may examine only Barbara's pattern $\mathrm{M}_{1} \subseteq$ $\mathrm{M}_{2} \subseteq \mathrm{M}_{3} \subseteq \ldots \subseteq \mathrm{M}_{\mathrm{n}}$, implying the premises $\mathrm{M}_{1} \cap \mathrm{M}_{2}{ }^{\prime}=\varnothing, \mathrm{M}_{2} \cap \mathrm{M}_{3}^{\prime}=\varnothing, \ldots$, $M_{n-1} \cap M_{n}{ }^{\prime}=\varnothing$, where $M_{i}{ }^{\prime}$ denotes the complement of $M_{i}$ in the universe of discourse, U. Any different Barbara type sorite being true, simultaneously with the "pattern Barbara", would impose conditions on U. For $\mathrm{n}=3$, if the "pattern Barbara", $\mathrm{S} \subseteq \mathrm{M} \subseteq \mathrm{P}$, is valid, then none of the other seven Barbara type syllogisms could be valid without imposing conditions on $\mathrm{U}$ : if both Celarent, $\mathrm{S} \subseteq \mathrm{M} \subseteq \mathrm{P}^{\prime}$, and Barbara are simultaneously valid, then $\mathrm{S}=\mathrm{M}=\emptyset$. If Camestres, $\mathrm{S} \subseteq \mathrm{M}^{\prime} \subseteq \mathrm{P}^{\prime}$, and Barbara are simultaneously valid, then $\mathrm{P}=\mathrm{M}$. Using term relabelings, all the other seven syllogisms of Barbara type can be reduced to the Barbara pattern. The relabelings are determined by which term is designated as being either $\mathrm{S}$ or $\mathrm{S}^{\prime}$, which one is labeled as either $\mathrm{P}$ or $\mathrm{P}^{\prime}$, which one is labeled either $\mathrm{M}$ or $\mathrm{M}$ ': none of the eight such relabelings, (nor the $\mathrm{P} \leftrightarrow \mathrm{S}$ relabeling), influence the syllogism's logical analysis. A unique "partitioning subset of U" characterizes the logical consequence of each of the Barbara, Darapti or Darii sorites. One argues that all the valid syllogisms are equivalent to either Barbara, Darapti or Darii, and that the moods and figures of Classical Syllogistics have mainly a historical value.
\end{abstract}

Keywords: Categorical Premises, Valid Categorical Argument, Valid Syllogism, Term Relabelings, Biliteral Sorites, Karnaugh Map.

\section{$1 \quad$ Preliminaries}

One uses the following notations and abbreviations: $U$ for the universe of discourse made of $2^{n}$ partitioning subsets corresponding to the $n$ terms of the sorite; $M^{\prime}$ for the complement in $\mathrm{U}$ of a set $\mathrm{M}$. No other set will be called a subset except a partitioning subset of U. (Boole, [1], calls the partitioning subsets "constituents".) Adjacency of set names will denote set intersections: for example, $\mathrm{M}_{1} \mathrm{M}_{2}$ denotes the intersection, $\mathrm{M}_{1} \cap \mathrm{M}_{2}$, of the sets $\mathrm{M}_{1}$ and $\mathrm{M}_{2}$. PCP will stand for pair of categorical premises; 
LC for Logical Consequence. Existential Import will be shortened to ei. A categorical statement connects two terms via one of the quantifiers A (All $\alpha$ is $\omega)$, E (No $\alpha$ is $\omega$ ), I (Some $\alpha$ is $\omega$ ), $\mathrm{O}$ (Some $\alpha$ is not $\omega$ ); $\alpha$ is called the subject of the statement and $\omega$ is called its predicate. Since George Boole [2] one can interpret each term as being a class (or set of elements). If the term appears in a universal statement, A or E, the term might be, possibly, an empty set. For example, if, in All $\alpha$ is $\omega$, the term $\omega$ is empty, then $\alpha$ is empty, too. In a particular statement, I or O, both terms are non-empty. Note that not $\omega$ means $\omega^{\prime}$ - the complement of $\omega$ in the universal set $U$; thus, $U=\alpha \cup \alpha^{\prime}=\omega \cup \omega^{\prime}$. ( $\cup$ is the union symbol; for convenience, it will be replaced by a + sign). An universal set with two terms is thus partitioned into four (nonintersecting) subsets: $U=(\alpha \cap \omega) \cup\left(\alpha^{\prime} \cap \omega\right) \cup\left(\alpha \cap \omega^{\prime}\right) \cup\left(\alpha^{\prime} \cap \omega^{\prime}\right)$, which, after replacing the intersection symbol by a juxtaposition, will be written as $U=\alpha \omega+\alpha^{\prime} \omega+\alpha \omega^{\prime}+\alpha^{\prime} \omega^{\prime}$. The not $\alpha$, or non $\alpha$, i.e., $\alpha^{\prime}$, and non $\omega$, i.e., $\omega^{\prime}$, are called negative terms, and $\alpha$ and $\omega$ are called positive terms. A syllogism contains three categorical statements - two premises and their proposed logical consequence (LC) or conclusion. Each of the two premises contains the middle term, most often denoted by $\mathrm{M}$, and two other terms, $\mathrm{P}$ and $\mathrm{S}$ which will appear again in the LC. The S, P, M terms are called positive terms and their complementary sets in $\mathrm{U}^{\prime} \mathrm{S}^{\prime}, \mathrm{P}^{\prime}, \mathrm{M}^{\prime}$, are the negative terms; together, S, P, M, S', $\mathrm{P}^{\prime}, \mathrm{M}^{\prime}$, are the indefinite terms. VCA, (or conclusive PCP), stands for valid categorical argument, i.e., stands for any PCP which entails a logical consequence (LC) of any of the eight formats $E\left(S^{*}, P^{*}\right), I\left(S^{*}, P^{*}\right)$, where $\mathrm{P}^{*} \in\left\{\mathrm{P}, \mathrm{P}^{\prime}\right\}, \mathrm{S}^{*} \in\left\{\mathrm{S}, \mathrm{S}^{\prime}\right\}$. For valid syllogisms, the Classical Syllogistics accepts, by definition, only these "standard" LC formats: A(S,P), E(S,P), I(S,P), O(S,P).

\section{Introduction}

Since Aristotle created it, for more than 2000 years, the Classical Syllogistics developed without the benefit of newer mathematics. We'll use matrices and set theory to simplify Classical Syllogistics - which, at the end of the 19th century, was described by Lewis Carroll [3] as follows: “...the ordinary textbooks of Formal Logic have elaborately discussed no less than nineteen different forms of Syllogisms - each with its own special and exasperating Rules, while the whole constitutes an almost useless machine, for practical purposes, many of the Conclusions being incomplete, and many quite legitimate forms being ignored", "As to syllogisms, I find that their nineteen forms, with about a score of others which the textbooks have ignored, can all be arranged under three forms, each with a very simple Rule of its own". "The theory that two negative premises prove nothing" is "another craze of 'The Logicians', fully as morbid as their dread of a negative Attribute" ("dread" of the S', P', M' terms).

Classical Syllogistics uses premises formulable only via positive terms, uses syllogistic figures, accepts as generating valid syllogisms only those PCPs which entail a logical consequence (LC) of one of the formats $\mathrm{A}(\mathrm{S}, \mathrm{P}), \mathrm{E}(\mathrm{S}, \mathrm{P}), \mathrm{I}(\mathrm{S}, \mathrm{P}), \mathrm{O}(\mathrm{S}, \mathrm{P})$. This paper uses instead a matrix of distinct PCPs formulable via both positive and negative terms, does not need the syllogistic figures, and accounts for any PCP which entails an LC - and thus generates a valid categorical argument (VCA), even if it is not a 
valid syllogism as per Classical Syllogistics' definition. Moreover, one argues that any valid categorical argument (VCA) can be expressed, via term relabelings - which do not alter the argument's logical content, as either a Barbara, Darapti or Darii valid syllogism - same idea as Carroll's, maybe taken one step further. Thus one advances the opinion that all the moods and figures of Classical Syllogistics retain only a limited, historical interest, since, in fact, only three different valid categorical arguments (VCAs) do exist, which may be chosen as being, e.g., Barbara, Darapti and Darii. One also argues that eliminating the middle term out of the logical consequences (LCs), even if it was started by Aristotle, is a somewhat misplaced endeavor because it weakens the LCs.

\section{The awkwardness of Classical Syllogistics}

In the Classical Syllogistics, the premises are restricted to being formulable only via the positive terms, S,P,M, and the LCs are restricted, by definition, to only the statements $\mathrm{A}(\mathrm{S}, \mathrm{P}), \mathrm{E}(\mathrm{S}, \mathrm{P}), \mathrm{I}(\mathrm{S}, \mathrm{P}), \mathrm{O}(\mathrm{S}, \mathrm{P})$. The first task is to find all pairs of categorical premises (PCPs) in which only the three positive terms, S, P, M, do appear - even if one may say that, surreptitiously, negative terms can appear, too, because $\mathrm{O}(\mathrm{S}, \mathrm{P})=\mathrm{I}\left(\mathrm{S}, \mathrm{P}^{\prime}\right), \mathrm{A}(\mathrm{M}, \mathrm{P})=\mathrm{E}\left(\mathrm{M}, \mathrm{P}^{\prime}\right), \mathrm{A}(\mathrm{P}, \mathrm{M})=\mathrm{E}\left(\mathrm{M}^{\prime}, \mathrm{P}\right)$, etc. But statements such as $\mathrm{I}\left(\mathrm{S}^{\prime}, \mathrm{P}^{\prime}\right)$ or $\mathrm{E}\left(\mathrm{M}^{\prime}, \mathrm{P}^{\prime}\right)$ are not allowed in Classical Syllogistics, since they cannot be rewritten as categorical statements containing only positive terms. According to Burris [4] George Boole had two objections to the structure of Classical Syllogistics: "Regarding syllogisms Boole did not care for the Aristotelian classification into Figures and Moods as it seemed rather arbitrary. In particular Boole did not like the requirement that the predicate of the conclusion had to be the major term in the premises." This last requirement which Boole did not like, is equivalent to accepting only the statements $\mathrm{A}(\mathrm{S}, \mathrm{P}), \mathrm{E}(\mathrm{S}, \mathrm{P}), \mathrm{I}(\mathrm{S}, \mathrm{P}), \mathrm{O}(\mathrm{S}, \mathrm{P})$ as syllogisms' LCs. If, as it happens, the LC is $\mathrm{A}(\mathrm{P}, \mathrm{S})$, (as entailed by Bramantip's premises), or it is $\mathrm{O}(\mathrm{P}, \mathrm{S})$, then the Classical Syllogistics, which does not accept such LCs, uses the fact that a $\mathrm{P} \leftrightarrow \mathrm{S}$ relabeling, i.e., a switch, or a permutation, in the names of the variables, (or in the order of premises, combined with the convention to denote by $\mathrm{P}$ the term - different from $\mathrm{M}$ - appearing in the firstly listed premise), will transform such pairs of categorical premises (PCPs), without changing their content, into PCPs which have the right LC types, as an "excuse" to disregard the A(P,S) LC and the PCPs whose LC is $\mathrm{O}(\mathrm{P}, \mathrm{S})$. Nevertheless, the Classical Syllogistics accepts Bramantip's premises, as they are, All P is M, All M is $\mathrm{S}$, but instead of using Bramantip's universal LC, All $\mathrm{P}$ is $\mathrm{S}$, it uses only the particular, existential import (ei) LC, of the same premises, after imposing an ei condition on $\mathrm{P}$, $\mathrm{P} \neq \varnothing$; thereafter, $\mathrm{A}(\mathrm{P}, \mathrm{S})$ implies the acceptable ei LC, "Some $\mathrm{S}$ is $\mathrm{P}$ ", of the (now) valid syllogism Bramantip. Therefore Classical Syllogistics tries to find each PCP, formulable via only positive terms, which, with or without existential import (ei), validly implies one of the statements $\mathrm{A}(\mathrm{S}, \mathrm{P}), \mathrm{E}(\mathrm{S}, \mathrm{P}), \mathrm{I}(\mathrm{S}, \mathrm{P}), \mathrm{O}(\mathrm{S}, \mathrm{P})$. According to Classical Syllogistics, the set of "PCP candidates" contains 64 PCPs: 16 pairings of the A,E,I,O statements - four per each premise, and, since in each premise one may reverse the order in which the two terms appear in the categorical statement, one mul- 
tiplies with another two possibilities per premise, i.e, one finally gets $16 * 4=64$ PCPs formulable via only positive terms. But this regards as distinct some superfluous syllogistic figures, generated by permuting the terms inside the $\mathrm{E}$ and I statements, even if the content of the statement changes only when permuting the arguments of the A and $\mathrm{O}$ statements. In reality only 36 PCPs are distinct, even if, with the help of the superfluous syllogistic figures, one arrives to a 64 "syllogistic figure" PCP count. It turns out that only 15 PCPs out of the 64 PCPs (mistakenly counted as distinct), entail one of the required LCs, A(S,P), E(S,P), I(S,P), or O(S,P). (In fact out of the 15 PCPs, only eight PCPs are distinct: the Ferio/Festino/Ferison/Fresison, Celarent/Cesare, Camestres/ Camenes, Darii/Datisi, and Disamis/Dimaris "groupings around slashes", homologate syllogistic figure distinctions without any PCP, (nor LC), content differences.) Out of the above mentioned 15 PCPs, five PCPs entail the A(S,P) conclusion - All S is $P$; thus if one also imposes an ei condition on $S$, i.e., $S \neq \varnothing$, then, the statement I(S,P) is also entailed by each one of the five PCPs (out of which only three PCPs are really distinct, since Celarent and Cesare, (resp. Camestres and Camenes), have the same PCP - modulo superfluous syllogistic figures). As already mentioned, Bramantip's PCP entails the A(P,S) logical consequence (LC) which is not on the above LC list - A(S,P), E(S,P), I(S,P), O(S,P); but, since, per $A(P, S), P$ is included in $\mathrm{S}$, if one imposes ei on $\mathrm{P}$, then the I(S,P) LC is also entailed - and one obtains Bramantip as another valid syllogism with a particular LC. Finally three other PCPs, (out of the 64 PCPs formulable via only positive terms), entail these LCs, respectively: All $\mathrm{M}$ is $\mathrm{S} \cap \mathrm{P}$, All $\mathrm{M}$ is $\mathrm{S} \cap \mathrm{P}^{\prime}$, All $\mathrm{M}$ is $\mathrm{S} \cap \mathrm{P}^{\prime}$, which are very different from the four acceptable LCs, first of all because M is not yet eliminated from the LC - the elimination of the middle term out of the LC is another questionable requirement of the Classical Syllogistics since it weakens the LC - see below. (On epistemological grounds, Aristotle himself introduced the elimination of the middle term: he wanted a syllogism to provide new knowledge - by establishing a direct connection between the $\mathrm{P}$ and $\mathrm{S}$ terms - deduced from the old knowledge contained in the two premises where the middle term had appeared in each of the premises.) But then, ei on $\mathrm{M}$ rescues these three PCPs, (out of which only two are distinct), because imposing $\mathrm{M} \neq \varnothing$, implies $\mathrm{S} \cap \mathrm{P} \neq \varnothing$, (resp. $\mathrm{S} \cap \mathrm{P}^{\prime} \neq \varnothing$ ), i.e., $\mathrm{I}(\mathrm{S}, \mathrm{P})$, (resp. $\mathrm{O}(\mathrm{S}, \mathrm{P})$ ), and thus approved LCs are again entailed. This way, after ei on $\mathrm{M}$ was imposed, and $\mathrm{M}$ was eliminated from the LC, one obtains the valid syllogisms Darapti, Felapton and Fesapo, whose PCPs are: All M is P, All M is S (Darapti), No M is P, All M is S (Felapton), and No P is $\mathrm{M}$, All $\mathrm{M}$ is S (Fesapo). Again, one can see that there is no logical content difference between Felapton and Fesapo - only their syllogistic figures differ, while their different names homologate a distinction without a difference. (To show that out of the 64 PCPs formulable via only positive terms, only 36 PCPs are distinct when superfluous figures are removed, one just has to observe that there are six $\mathrm{P}$ premises, (resp. $\mathrm{S}$ premises), formulable via only positive terms: they pair up to only 36 PCPs.) At last count, in Classical Syllogistics, there are 15 PCPs whose LCs may be directly expressed in one of the four LC formats homologated as correct by the Classical Syllogistics, and, via ei on S, five of the 15 PCPs produce a second LC, I(S,P), of the correct type, and, there are four other PCPs which, via ei on $\mathrm{P}$ or $\mathrm{M}$, entail the $\mathrm{I}(\mathrm{S}, \mathrm{P})$ or $\mathrm{O}(\mathrm{S}, \mathrm{P}) \mathrm{LCs}$ - and thus raise the total count to 24 valid syllogisms, six per (lucky) 
syllogistic figure. See Copi [5] and Hurley [6].

\section{The "reference system" provided by the universal set, U, for analyzing simple biliteral sorites}

Instead of following the Classical Syllogistics in its search for PCPs which entail an LC, while subjecting both PCPs and LCs to the above and other preconditions, (such as "two negative premises are not allowed"), one uses the reference system provided by the universal set, to tackle the problem of finding LCs out of categorical premises, without any constraints but logical entailment: if the premises are true, the conclusion should be necessarily true, also. Firstly one notices that the Barbara and Darapti syllogisms and sorites contain only universal premises $\mathrm{A}$ and $\mathrm{E}$, where, by obversion, the A statements can be replaced by $\mathrm{E}$ statements and vice-versa, since $\mathrm{A}\left(\mathrm{M}_{\mathrm{j}}, \mathrm{M}_{\mathrm{k}}\right)=\mathrm{E}\left(\mathrm{M}_{\mathrm{j}}, \mathrm{M}_{\mathrm{k}}{ }^{\prime}\right)$, meaning $\mathrm{M}_{\mathrm{j}} \mathrm{M}_{\mathrm{k}}{ }^{\prime}:=\mathrm{M}_{\mathrm{j}} \cap \mathrm{M}_{\mathrm{k}}{ }^{\prime}=\varnothing$. In a universal set, $\mathrm{U}$, containing $\mathrm{n}$ terms, such a universal premise would empty $2^{\mathrm{n}-2}$ subsets, and would be leaving $3 * 2^{\mathrm{n}-2}$ subsets about which nothing is yet asserted. The only LC one might hope to obtain via emptying subsets is that one or more terms will end up with all their respective subsets emptied, except for one subset about which the premises do not assert anything. The resulting LC is that the whole term equals one of its $2^{\mathrm{n}-1}$ subsets. If one wants to impose an ei condition on such a term, it will be clear which one of the term's subsets will be non-empty: the only one subset which was not emptied, after all the universal premises were applied! In this Section, the numbering of the formulas and figures will contain a (b) if they refer to the Barbara type syllogisms or sorites, will contain a (d), as in Darapti, if they refer to the Darapti type syllogisms or sorites, and will contain a (p), as in particular (premise), if they refer to Darii type syllogisms or sorites. Barbara type premises amount to a Barbara-chain pattern of inclusions, $\left(\mathrm{b}_{0}\right) \mathrm{M}_{1} \subseteq \mathrm{M}_{2} \subseteq \mathrm{M}_{3} \subseteq \ldots \subseteq \mathrm{M}_{\mathrm{n}}$. Darapti type premises amount to a Darapti-chain pattern of inclusions, $\left(\mathrm{d}_{0}\right) \mathrm{M}_{1} \subseteq \mathrm{M}_{2}, \mathrm{M}_{1} \subseteq \mathrm{M}_{3}, \ldots, \mathrm{M}_{1} \subseteq \mathrm{M}_{\mathrm{n}}$. The result of applying either chain of $\mathrm{n}-1$ premises to the above $\mathrm{n}$ terms is that two terms, (resp. one term), in the case of Barbara's, (resp. Darapti's), chain of premises will be left with all the subsets emptied - except for one subset about which (the emptying) premises do not assert anything. Clearly $\left(b_{0}\right)$ implies $\left(\mathrm{d}_{0}\right)$. The difference is also seen in the fact that $\left(\mathrm{b}_{0}\right)$ entails two LCs, while $\left(\mathrm{d}_{0}\right)$ entails only one LC - see below. Take, e.g., Celarent's premises, No M is P, All S is M. (Notice the convention to firstly list the premise containing the $\mathrm{P}$ term - since the LC does not depend on the premises' order, this convention would be pointless - but for the fact that for defining the syllogistic figures, (and for recovering the valid syllogisms' historical names), the order of the premises has to be uniformly the same; in Classical Syllogistics the real restriction comes from the fact that one accepts only PCPs whose LCs have one of the four homologated formats, $\mathrm{A}(\mathrm{S}, \mathrm{P}), \mathrm{E}(\mathrm{S}, \mathrm{P}), \mathrm{I}(\mathrm{S}, \mathrm{P}), \mathrm{O}(\mathrm{S}, \mathrm{P})$.) Celarent's premises may be rewritten as Barbara's premises in which $\mathrm{P}^{\prime}$ appears instead of $\mathrm{P}$ : All M is $\mathrm{P}^{\prime}$, All S is M. 
This shows that via a relabeling $\mathrm{P} \leftrightarrow \mathrm{P}^{\prime}$ Barbara becomes Celarent and vice-versa. Writing Barbara's premises as $\mathrm{E}\left(\mathrm{M}, \mathrm{P}^{\prime}\right) \mathrm{E}\left(\mathrm{M}^{\prime}, \mathrm{S}\right)$, and Bramantip premises as $\mathrm{E}\left(\mathrm{M}^{\prime}, \mathrm{P}\right) \mathrm{E}\left(\mathrm{M}, \mathrm{S}^{\prime}\right)$, one sees that these two PCPs turn out to be equivalent via a relabeling $\mathrm{P} \leftrightarrow \mathrm{P}^{\prime}, \mathrm{S} \leftrightarrow \mathrm{S}^{\prime}, \mathrm{M} \leftrightarrow \mathrm{M}^{\prime}$, (or, via a relabeling $\mathrm{P} \leftrightarrow \mathrm{S}$ ). The universal LC of Bramantip premises, (All P is M, All M is S), (therefore) "All P is S", is unacceptable to Classical Syllogistics, even if Bramantip's premises are clearly of Barbara's type. Only by adding $\mathrm{P} \neq \varnothing$ one can extract Bramantip as an ei valid syllogism! The Darii syllogisms and sorites contain only one particular premise and the rest are the universal premises A and E. As mentioned, Lewis Carroll, expressed very clearly the idea of syllogisms being of three different types. All the premises of the first two types are universal, the Darii type has also one particular premise, which will be always written as $\mathrm{M}_{1} \mathrm{M}_{2}$ := $\mathrm{M}_{1} \cap \mathrm{M}_{2} \neq \varnothing$, (meaning "Some $\mathrm{M}_{1}$ is $\mathrm{M}_{2}$ "). In a Darii sorite with $\mathrm{n}$ terms, the LC one can hope for, will say that out of the $2^{\mathrm{n}-2}$ subsets of $\mathrm{M}_{1} \mathrm{M}_{2} \neq \varnothing$ which are possibly nonempty, the n-2 universal premises will empty all but a unique subset of $\mathrm{M}_{1} \mathrm{M}_{2}$ which will represent the LC of the Darii sorite. For a 2-term universe, $n=2$, the one premise, $\mathrm{M}_{1} \mathrm{M}_{2}=\varnothing$, empties one subset and implicitly provides two LCs: $\mathrm{M}_{1}=$ $\mathrm{M}_{1} \mathrm{M}_{2}$ and $\mathrm{M}_{2}{ }^{\prime}=\mathrm{M}_{1}{ }^{\prime} \mathrm{M}_{2}$ '. For a 3-term universe, $\mathrm{n}=3$, Barbara's premises, $\mathrm{M}_{1} \mathrm{M}_{2}^{\prime}=\varnothing$ and $\mathrm{M}_{2} \mathrm{M}_{3}{ }^{\prime}=\varnothing$, empty four subsets $\mathrm{M}_{1} \mathrm{M}_{2}{ }^{\prime} \mathrm{M}_{3}+\mathrm{M}_{1} \mathrm{M}_{2}{ }^{\prime} \mathrm{M}_{3}{ }^{\prime}=\varnothing \quad$ and $\mathrm{M}_{1} \mathrm{M}_{2} \mathrm{M}_{3}{ }^{\prime}+\mathrm{M}_{1}{ }^{\prime} \mathrm{M}_{2} \mathrm{M}_{3}{ }^{\prime}=\varnothing$. Implicitly, Barbara's premises provide two LCs: $\mathrm{M}_{1}=$ $\mathrm{M}_{1} \mathrm{M}_{2} \mathrm{M}_{3}$ and $\mathrm{M}_{3}{ }^{\prime}=\mathrm{M}_{1}{ }^{\prime} \mathrm{M}_{2}{ }^{\prime} \mathrm{M}_{3}$ '. The four subsets about which the premises do not assert anything are $\mathrm{M}_{1} \mathrm{M}_{2} \mathrm{M}_{3}, \mathrm{M}_{1}{ }^{\prime} \mathrm{M}_{2} \mathrm{M}_{3}, \mathrm{M}_{1}{ }^{\prime} \mathrm{M}_{2}{ }^{\prime} \mathrm{M}_{3}$ and $\mathrm{M}_{1}{ }^{\prime} \mathrm{M}_{2}{ }^{\prime} \mathrm{M}_{3}{ }^{\prime}$. One can also check that these "remaining" subsets still satisfy $U=M_{1}+M_{1}^{\prime}=M_{2}+M_{2}{ }^{\prime}=M_{3}+M_{3}$ ' and $\mathrm{M}_{1} \subseteq \mathrm{M}_{2} \subseteq \mathrm{M}_{3}$. Nothing was explicitly said about the "remaining" four subsets. But implicitly one have gotten two LCs, describing a unique characteristic of two of these subsets, $\mathrm{M}_{1} \mathrm{M}_{2} \mathrm{M}_{3}$ and $\mathrm{M}_{1}{ }^{\prime} \mathrm{M}_{2}{ }^{\prime} \mathrm{M}_{3}$ ', about which Barbara's premises do not assert anything explicitly, namely,

$\left(b_{1}\right) M_{1}=M_{1} M_{2} M_{3}$ and $M_{3}^{\prime}=M_{1}{ }^{\prime} M_{2}^{\prime} M_{3}^{\prime}$ since the sets $M_{1}$ and $M_{3}^{\prime}$ have each three empty subsets and one subset which remains, possibly, non-empty. An existential import condition imposed on $\mathrm{M}_{1}$ or/and $\mathrm{M}_{3}$ ' will assert that $\mathrm{M}_{1} \mathrm{M}_{2} \mathrm{M}_{3}$ or/and $\mathrm{M}_{1}{ }^{\prime} \mathrm{M}_{2}{ }^{\prime} \mathrm{M}_{3}$ ' are not empty, and thus, e.g., an LC of the type "Some $\mathrm{M}_{2}$ is $\mathrm{M}_{3}$ ", or "Some $\mathrm{M}_{1}$ is $\mathrm{M}_{3}$ " could be inferred. (One also sees that there is nothing magic about eliminating any of the terms - once the "smallest" set is non-empty any two sets out of three will have Some(thing) in them. But the elimination of the middle term $\mathrm{M}_{2}$ in Barbara, (resp. Barbari), is, I believe, unfortunate: instead of being told that "All $\mathrm{M}_{1}$ is $\mathrm{M}_{1} \mathrm{M}_{2} \mathrm{M}_{3}$ “, i.e., $\mathrm{M}_{1}=\mathrm{M}_{1} \mathrm{M}_{2} \mathrm{M}_{3}$, (resp. $\mathrm{M}_{1} \mathrm{M}_{2} \mathrm{M}_{3} \neq \varnothing$ ), one is left with only, in principle, the weaker information that $\mathrm{M}_{1}=\mathrm{M}_{1} \mathrm{M}_{3}=\mathrm{M}_{1} \mathrm{M}_{2} \mathrm{M}_{3}+\mathrm{M}_{1} \mathrm{M}_{2} \mathrm{M}_{3}$, (resp. $\mathrm{M}_{1} \mathrm{M}_{3} \neq \varnothing$ ). Replacing the precise $\mathrm{LC}$, “All $\mathrm{M}_{1}$ is $\mathrm{M}_{1} \mathrm{M}_{2} \mathrm{M}_{3}$ ”, by the standard universal LC, "All $M_{1}$ is $M_{3}$ ", means that $M_{1}$ might be "spread" onto the subsets $M_{1} M_{2} M_{3}$ or $\mathrm{M}_{1} \mathrm{M}_{2} \mathrm{M}_{3}$ - which is not entirely correct, since one already knows that $\mathrm{M}_{1} \mathrm{M}_{2} \mathrm{M}_{3}$ is empty. Both LCs from $\left(\mathrm{b}_{1}\right)$ satisfy the "one subset LC paradigm": one has an LC if 
and only if the premises pinpoint a unique subset of U. One can also list the four subsets about which the premises do not explicitly assert anything:

(b $\mathrm{b}_{2} \mathrm{M}_{1} \mathrm{M}_{2} \mathrm{M}_{3}, \mathrm{M}_{1}{ }^{\prime} \mathrm{M}_{2} \mathrm{M}_{3}, \mathrm{M}_{1}{ }^{\prime} \mathrm{M}_{2} \mathrm{M}_{3}, \mathrm{M}_{1}{ }^{\prime} \mathrm{M}_{2} \mathrm{M}_{3}$ ' - although, as said, implicitly, two LCs were obtained: $\mathrm{M}_{1}=\mathrm{M}_{1} \mathrm{M}_{2} \mathrm{M}_{3}$ and $\mathrm{M}_{3}{ }^{\prime}=\mathrm{M}_{1}{ }^{\prime} \mathrm{M}_{2}{ }^{\prime} \mathrm{M}_{3}{ }^{\prime}$. It turns out that the analog formulas for the two Barbara's LCs and for the list of subsets about which the Barbara type sorites with $\mathrm{n}$ terms do not assert anything, are: (b $\left.{ }_{3}\right) \mathrm{M}_{1}=\mathrm{M}_{1} \mathrm{M}_{2} \mathrm{M}_{3} \ldots \mathrm{M}_{\mathrm{n}-1} \mathrm{M}_{\mathrm{n}}$ and $\mathrm{M}_{\mathrm{n}}{ }^{\prime}=\mathrm{M}_{1}{ }^{\prime} \mathrm{M}_{2}{ }^{\prime} \mathrm{M}_{3} \mathrm{M}_{4}{ }^{\prime} \ldots \mathrm{M}_{\mathrm{n}-1^{\prime}} \mathrm{M}_{\mathrm{n}}{ }^{\prime}$ - the two exact LCs: one has found out that each of $\mathrm{M}_{1}$ and $\mathrm{M}_{\mathrm{n}}$ ' sets are made of one (possibly non-empty) subset - all the other $2^{n-1}-1$ subsets of each of $M_{1}$ and $M_{n}$ ' are empty.

(b $\left.\mathrm{b}_{4}\right) \quad \mathrm{M}_{1} \mathrm{M}_{2} \mathrm{M}_{3} \ldots \mathrm{M}_{\mathrm{n}-1} \mathrm{M}_{\mathrm{n}}, \quad \mathrm{M}_{1}{ }^{\prime} \mathrm{M}_{2} \mathrm{M}_{3} \ldots \mathrm{M}_{\mathrm{n}-1} \mathrm{M}_{\mathrm{n}}, \quad \mathrm{M}_{1}{ }^{\prime} \mathrm{M}_{2} \mathrm{M}_{3} \ldots \mathrm{M}_{\mathrm{n}-1} \mathrm{M}_{\mathrm{n}}$, $\mathrm{M}_{1}{ }^{\prime} \mathrm{M}_{2}{ }^{\prime} \mathrm{M}_{3}{ }^{\prime} \mathrm{M}_{4} \ldots \mathrm{M}_{\mathrm{n}-1} \mathrm{M}_{\mathrm{n}}, \ldots, \mathrm{M}_{1}{ }^{\prime} \mathrm{M}_{2}{ }^{\prime} \mathrm{M}_{3}{ }^{\prime} \ldots \mathrm{M}_{\mathrm{n}-1}{ }^{\prime} \mathrm{M}_{\mathrm{n}}, \quad \mathrm{M}_{1}{ }^{\prime} \mathrm{M}_{2}{ }^{\prime} \mathrm{M}_{3}{ }^{\prime} \mathrm{M}_{4}{ }^{\prime} \ldots \mathrm{M}_{\mathrm{n}-1}{ }^{\prime} \mathrm{M}_{\mathrm{n}}{ }^{\prime}$, is the complete list of the $(n+1)$ subsets about which the premises of a Barbara sorite do not assert anything explicitly; the first and the last became the two LCs from the formula $\left(b_{3}\right)$; the total number of emptied subsets is $2^{n}-(n+1)$. Note that the union of the first two subsets in $\left(b_{4}\right)$ equals $M_{2}$, the union of the first three subsets in $\left(b_{4}\right)$ equals $M_{3}$, the union of the first four subsets in $\left(b_{4}\right)$ equals $M_{4}, \ldots$, the union of the first $n$ subsets in $\left(b_{4}\right)$ equals $M_{n}$, while the $(n+1)$ subset represents $M_{n}{ }^{\prime}$, the union of the last two subsets in $\left(b_{4}\right)$ equals $M_{n-1}{ }^{\prime}, \ldots$, and the union of the last $n$ subsets in $\left(b_{4}\right)$ equals $M_{1}$, which are exactly the relationships necessary to verify that $\mathrm{U}=\mathrm{M}_{1}+\mathrm{M}_{1}{ }^{\prime}=\mathrm{M}_{2}+\mathrm{M}_{2}{ }^{\prime}=\ldots=\mathrm{M}_{\mathrm{n}}+\mathrm{M}_{\mathrm{n}}{ }^{\prime}$. It results that $\left(\mathrm{b}_{4}\right)$ spells in a more precise, "Karnaugh-map manner", what Barbara's chain inclusions asserted in $\left(\mathrm{b}_{0}\right)$ :

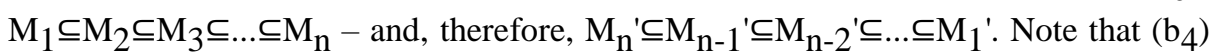
implies $\left(b_{3}\right)$, and that $\left(b_{3}\right)$ and $\left(b_{4}\right)$ are valid for $n=2$ : one has two implicit LCs; $2^{2}$ $(2+1)=1=$ one empty subset; a list of $2+1=3$ subsets about which the universal premise does not assert anything. Also $\left(b_{3}\right)$ and $\left(b_{4}\right)$ are valid for $n=3$ : there are two implicit LCs; $2^{3}-(3+1)=4=$ four empty subsets; a list of $3+1=4$ subsets about which the universal premises do not assert anything. To prove $\left(\mathrm{b}_{4}\right)$ by induction, suppose that the list $\mathrm{M}_{1} \mathrm{M}_{2} \mathrm{M}_{3} \ldots \mathrm{M}_{\mathrm{n}-1} \mathrm{M}_{\mathrm{n}}, \quad \mathrm{M}_{1}{ }^{\prime} \mathrm{M}_{2} \mathrm{M}_{3} \ldots \mathrm{M}_{\mathrm{n}-1} \mathrm{M}_{\mathrm{n}}, \quad \mathrm{M}_{1}{ }^{\prime} \mathrm{M}_{2}{ }^{\prime} \mathrm{M}_{3} \ldots \mathrm{M}_{\mathrm{n}-1} \mathrm{M}_{\mathrm{n}}$, $\mathrm{M}_{1}{ }^{\prime} \mathrm{M}_{2}{ }^{\prime} \mathrm{M}_{3}{ }^{\prime} \mathrm{M}_{4} \ldots \mathrm{M}_{\mathrm{n}-1} \mathrm{M}_{\mathrm{n}}, \ldots, \mathrm{M}_{1}{ }^{\prime} \mathrm{M}_{2}{ }^{\prime} \mathrm{M}_{3}{ }^{\prime} \ldots \mathrm{M}_{\mathrm{n}-1}{ }^{\prime} \mathrm{M}_{\mathrm{n}}, \mathrm{M}_{1}{ }^{\prime} \mathrm{M}_{2}{ }^{\prime} \mathrm{M}_{3}{ }^{\prime} \mathrm{M}_{4}^{\prime} \ldots \mathrm{M}_{\mathrm{n}-1}{ }^{\prime} \mathrm{M}_{\mathrm{n}}{ }^{\prime}$ contains the only $n+1$ subsets which the $n-1$ premises $\left(b_{0}\right)$ did not empty. One now doubles the number of subsets (or constituents) of $U$ by adding another term, $M_{n+1}$, and another premise to $\left(b_{0}\right): M_{n} M_{n+1}=\varnothing$. The "old" subsets receive an extra index, $\mathrm{M}_{\mathrm{n}+1}$, and the new subsets, mirrored, say, to the right, on a Karnaugh-map with two rows receive the extra index, $M_{n+1}$. (See the Figure 1 below for an example of a Karnaugh map for $\mathrm{n}=5$, obtained and indexed via mirroring, on which it was depicted the effect of the particular premise, $M_{1} M_{2} \neq \varnothing$.) The newest premise, $M_{n} M_{n+1}=\varnothing$, does not act on the subsets which received the extra index $M_{n+1}$, but it empties all the mirrored subsets which were not emptied by the n-1 premises, and which, at their mirrored creation, received the extra index $M_{n+1}$, except for the subset 
$M_{1}{ }^{\prime} M_{2}{ }^{\prime} M_{3}{ }^{\prime} M_{4}{ }^{\prime} \ldots M_{n-1}{ }^{\prime} M_{n}{ }^{\prime} M_{n+1}{ }^{\prime}$ - the mirror image of $M_{1}{ }^{\prime} M_{2}{ }^{\prime} M_{3}{ }^{\prime} M_{4}^{\prime} \ldots M_{n-1}{ }^{\prime}$ $M_{n}{ }^{\prime} M_{n+1}$, because this latter subset did not contain $M_{n}$. QED. (The Karnaugh maps, or K-maps, were introduced firstly by Alan Marquand [7] in 1881, only one year after John Venn [8] used the 3-circle diagram for representing the three terms of a categorical syllogism; then these maps were rediscovered and improved by Veitch [9] and Karnaugh [10]. For more details about Karnaugh maps on any number of rows, see Abdalla [11]. The Figure 1 shows the 2-row K-map for $n=5$, with only the effect of the particular premise $\mathrm{M}_{1} \mathrm{M}_{2} \neq \varnothing$ depicted on it. It was obtained by successively mirroring to the right the $K$-map for $n=2$, on which $M_{1} M_{2}$ was blackened. See below the discussion

of

Darii

sorite.)

$\begin{array}{llllllll}\mathrm{M}_{3} & \mathrm{M}_{3}{ }^{\prime} & \mathrm{M}_{3}{ }^{\prime} & \mathrm{M}_{3} & \mathrm{M}_{3} & \mathrm{M}_{3}{ }^{\prime} & \mathrm{M}_{3}{ }^{\prime} & \mathrm{M}_{3}\end{array}$

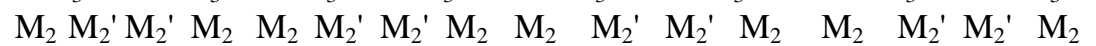

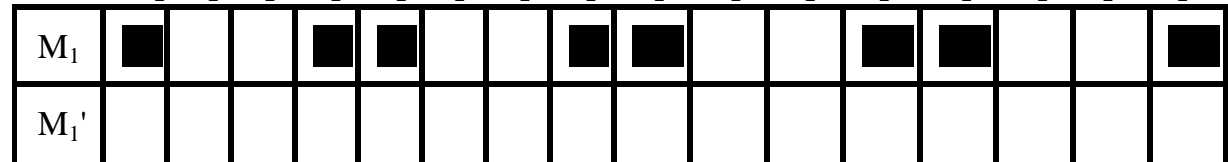

Fig. 1. $\mathrm{M}_{4}$

$\mathrm{M}_{5}$

$\mathrm{M}_{4}^{\prime} \quad \mathrm{M}_{4}^{\prime}$

$\mathrm{M}_{5}{ }^{\prime}$

For the 3-term syllogism, applying the two premises of the Darapti's pattern, $\mathrm{M}_{1} \mathrm{M}_{2}{ }^{\prime}=\varnothing$ and $\mathrm{M}_{1} \mathrm{M}_{3}^{\prime}=\varnothing$, one sees that only three subsets, (not four), will be emptied - since the subset $\mathrm{M}_{1} \mathrm{M}_{2}{ }^{\prime} \mathrm{M}_{3}$ ' is emptied by each of the two premises. Nothing is explicitly said about the other five subsets. But implicitly one have already gotten one LC, describing a unique characteristic of the subset $\mathrm{M}_{1} \mathrm{M}_{2} \mathrm{M}_{3}$, about which Darapti's premises do not assert anything explicitly, namely: (d $\left.\mathrm{d}_{1}\right) \quad \mathrm{M}_{1}=\mathrm{M}_{1} \mathrm{M}_{2} \mathrm{M}_{3}$ since the set $\mathrm{M}_{1}$ has three empty subsets.

This LC satisfies the "one subset LC paradigm": one has an LC if and only if the premises pinpoint a unique subset of U. It is simpler than in Barbara's syllogism case to list the five subsets about which the premises do not explicitly assert anything: $\left(d_{2}\right) M_{1} M_{2} M_{3}$ and $M_{1}$ ', since Darapti's premises do not assert anything about any of the subsets of $\mathrm{M}_{1}{ }^{\prime}$. For the Darapti type sorites with $\mathrm{n}$ terms the formulas $\left(\mathrm{d}_{1}\right)$ and $\left(\mathrm{d}_{2}\right)$ become: $\left(\mathrm{d}_{3}\right) \mathrm{M}_{1}=\mathrm{M}_{1} \mathrm{M}_{2} \mathrm{M}_{3} \ldots \mathrm{M}_{\mathrm{n}-1} \mathrm{M}_{\mathrm{n}}$ - this LC satisfies the "one subset LC paradigm"; the other $2^{\mathrm{n}-1}-1$ subsets of of $\mathrm{M}_{1}$ are empty. $\left(\mathrm{d}_{4}\right) \mathrm{M}_{1} \mathrm{M}_{2} \mathrm{M}_{3} \ldots \mathrm{M}_{\mathrm{n}-1} \mathrm{M}_{\mathrm{n}}$ and $\mathrm{M}_{1}{ }^{\prime}$ are the sets about which the premises of a Darapti sorite do not assert anything explicitly; the first of the two sets in the $\left(\mathrm{d}_{4}\right)$ 2-set list, represents the LC of the Darapti's sorite from the formula $\left(\mathrm{d}_{3}\right)$; the total number of emptied subsets is $2^{\mathrm{n}-1}-1$. Barbara and Darapti sorites have the same first premise. Since Darapti's syllogism and sorite premises do not assert anything about any subset of $\mathrm{M}_{1}{ }^{\prime}$, the second LCs will be lost for any $n>2$. To prove $\left(d_{3}\right)$ and $\left(d_{4}\right)$ by induction, suppose the $n-1$ Darapti premises, $\mathrm{M}_{1} \mathrm{M}_{2}^{\prime}=\varnothing, \mathrm{M}_{1} \mathrm{M}_{3}^{\prime}=\varnothing, \ldots, \mathrm{M}_{1} \mathrm{M}_{\mathrm{n}}^{\prime}=\varnothing$, empty all the subsets of $\mathrm{M}_{1}$ except 
$\mathrm{M}_{1} \mathrm{M}_{2} \ldots \mathrm{M}_{\mathrm{n}}$, and suppose that nothing is asserted about the set $\mathrm{M}_{1}{ }^{\prime}$. Then, one doubles the number of subsets by adding another term: $M_{n+1}$. The $M_{n+1}$ index is added to the "old subsets", and the new, mirrored subsets receive the $\mathrm{M}_{\mathrm{n}+1}$ ' additional index. The only two subsets of the set $\mathrm{M}_{1}$ which were not already emptied by the above $n-1$ Darapti premises are $M_{1} M_{2} \ldots M_{n} M_{n+1}$ and $M_{1} M_{2} \ldots M_{n} M_{n+1}$. The Addition of the $n^{\text {th }}$ Darapti premise, $M_{1} M_{n+1}=\varnothing$, will empty the subset $M_{1} M_{2} \ldots M_{n}$ $M_{n+1}$ '. Also, the $n^{\text {th }}$ premise does not assert anything about the set $M_{1}{ }^{\prime}$. QED.

Concerning Darii's particular premise, when one has $n$ terms, the set $M_{1} M_{2}$ contains $2^{\mathrm{n}-2}$ subsets, and $\mathrm{M}_{1} \mathrm{M}_{2} \neq \varnothing$ means that all these subsets might be non-empty - at least one of them is - and this does not sound like a "one subset paradigm LC". Therefore, to obtain such an LC, one should choose the second, third, etc., universal premises, in such a way that, for any $k>2$, only, e.g., the subset $M_{1} M_{2} M_{3} \ldots M_{k-1} M_{k}$ will remain non-empty. Thus the role of the universal premise in a Disamis, Darii, Ferio, Bocardo, Baroco, etc., 3-term syllogism, is to empty the subset $\mathrm{M}_{1} \mathrm{M}_{2} \mathrm{M}_{3}$. The difference between these syllogisms consists in how they relabel the eight subsets of $U$. One can relabel $\mathrm{M}_{1}, \mathrm{M}_{2}, \mathrm{M}_{3}$, by using the standard names for the syllogistic variables, S, P, M, S', P', M', in various ways such that the "pattern" Darii premises, $\mathrm{M}_{1} \mathrm{M}_{2} \neq \varnothing$ and either $\mathrm{M}_{1} \mathrm{M}_{3}^{\prime}=\varnothing$ or $\mathrm{M}_{2} \mathrm{M}_{3}^{\prime}=\varnothing$, will represent any and all of the syllogisms Disamis, Darii, Ferio, Bocardo, and Baroco. Similarly, all the syllogisms of type Barbara, (resp. Darapti), are equivalent to each other - see Section 5.

The difference between a sorite whose all premises are universal and one that has one particular premise, is that the "mission" of all the universal premises in a Barbara or Darapti type sorite is to empty all subsets of a set except one - that one subset is then the subject of the "one subset LC" - for example, one term, such as $\mathrm{M}_{1}$, is reduced to just one partitioning subset of $\mathrm{U}$; the "mission" of all the universal premises in a Darii type sorite is to empty, except one, all the subsets about which the particular premise asserts that at least one of them is non-empty - and one obtains, again, a "one subset LC" - which, now, is definitely not empty. In an universe with $\mathrm{n}$ terms and $2^{\text {n }}$ subsets, the Barbara and Darapti sorites empty $2^{\mathrm{n}-1}-1$ subsets of the set which will provide the LC of the sorite. The "mission" of leaving just one non-empty subset of $\mathrm{M}_{1} \mathrm{M}_{2} \neq \varnothing$ once all the $\mathrm{n}-2$ universal premises of a Darii type sorite are applied, is accomplished, if the $\mathrm{n}-2$ universal premises of the Darii sorite empty $2^{\mathrm{n}-2}-1$ subsets out of the $2^{\mathrm{n}-2}$ subsets of $\mathrm{M}_{1} \mathrm{M}_{2} \neq \varnothing$. One lists the possible premises of a Darii type sorite for $\mathrm{k}=3,4, \ldots, \mathrm{n}$. For each $\mathrm{k}$ the pattern is as follows: For $\mathrm{k}=3$ one needs to empty just the subset $\mathrm{M}_{1} \mathrm{M}_{2} \mathrm{M}_{3}{ }^{\prime}$. This can be done by adding as a $2^{\text {nd }}$ premise either $\mathrm{M}_{1} \mathrm{M}_{3}{ }^{\prime}=\varnothing$ or $\mathrm{M}_{2} \mathrm{M}_{3}{ }^{\prime}=\varnothing$. Then, one can notice, that for $\mathrm{k}=4$, only the subset $\mathrm{M}_{1} \mathrm{M}_{2} \mathrm{M}_{3} \mathrm{M}_{4}{ }^{\prime}$, the mirror image of the $\mathrm{M}_{1} \mathrm{M}_{2} \mathrm{M}_{3} \mathrm{M}_{4} \neq \varnothing$ needs to be emptied. This can be accomplished by adding, as a $3^{\text {rd }}$ premise, any one of the following three relations, $\mathrm{M}_{1} \mathrm{M}_{4}{ }^{\prime}=\varnothing$, or $\mathrm{M}_{2} \mathrm{M}_{4}^{\prime}=\varnothing$, or $\mathrm{M}_{3} \mathrm{M}_{4}{ }^{\prime}=\varnothing$. Either one of these three statements, when added as a third premise would assure that $\mathrm{M}_{1} \mathrm{M}_{2} \mathrm{M}_{3} \mathrm{M}_{4}^{\prime}=\varnothing$. It results that a Darii type syllogism can 
be extended to a Darii type sorite via either Darapti or Barbara chain links, "based" (or anchored) at any term. Another way to express the multitude of premise choices is as follows. For any term $\mathrm{k} \geq 3$ one has $\mathrm{k}-1$ choices for adding the $(\mathrm{k}-1)^{\text {th }}$ premise: $\mathrm{M}_{1} \mathrm{M}_{\mathrm{k}}^{\prime}=\varnothing, \mathrm{M}_{2} \mathrm{M}_{\mathrm{k}}^{\prime}=\varnothing, \mathrm{M}_{3} \mathrm{M}_{\mathrm{k}}^{\prime}=\varnothing, \ldots, \mathrm{M}_{\mathrm{k}-2} \mathrm{M}_{\mathrm{k}}^{\prime}=\varnothing, \mathrm{M}_{\mathrm{k}-1} \mathrm{M}_{\mathrm{k}}^{\prime}=\varnothing$. One obtains a Darii type sorite, by using any path of premise choices, one choice per each set of the $\mathrm{k}-1$ premises acceptable for addition as the $(\mathrm{k}-1)^{\text {th }}$ premise for each present term $\mathrm{M}_{\mathrm{k}}$, where $3 \leq \mathrm{k} \leq \mathrm{n}$. Any such "path of premise choices" will result in a Darii type sorite with $n$ terms and $n-1$ premises. The first, particular, premise of a Darii sorite is always $\mathrm{M}_{1} \mathrm{M}_{2} \neq \varnothing$. Then the three simplest paths for obtaining a Darii sorite would be to use Darapti-chained universal premises "based" either on $\mathrm{M}_{1}$, (for each $\mathrm{M}_{\mathrm{k}}$ always choose the first premise from the list of $\mathrm{k}-1$ possible premises), or on $\mathrm{M}_{2}$, (for each $\mathrm{M}_{\mathrm{k}}$ always choose the second premise from the list of $\mathrm{k}-1$ possible premises), or to use a Barbara chain started at $\mathrm{M}_{3}$ (for each term $\mathrm{M}_{\mathrm{k}}$ always choose the last premise from the list of $\mathrm{k}-1$ possible premises): ( $\left.\mathrm{p}_{1}\right) \quad \mathrm{M}_{1} \mathrm{M}_{3}^{\prime}=\varnothing, \quad \mathrm{M}_{1} \mathrm{M}_{4}^{\prime}=\varnothing, \quad \mathrm{M}_{1} \mathrm{M}_{5}^{\prime}=\varnothing, \quad \ldots, \quad \mathrm{M}_{1} \mathrm{M}_{\mathrm{n}-1}=\varnothing, \quad \mathrm{M}_{1} \mathrm{M}_{\mathrm{n}}^{\prime}=\varnothing$ ( $\left.\mathrm{p}_{2}\right) \quad \mathrm{M}_{2} \mathrm{M}_{3}^{\prime}=\varnothing, \quad \mathrm{M}_{2} \mathrm{M}_{4}^{\prime}=\varnothing, \quad \mathrm{M}_{2} \mathrm{M}_{5}^{\prime}=\varnothing, \quad \ldots, \quad \mathrm{M}_{2} \mathrm{M}_{\mathrm{n}-1}=\varnothing, \quad \mathrm{M}_{2} \mathrm{M}_{\mathrm{n}}^{\prime}=\varnothing$ ( $\left.\mathrm{p}_{3}\right) \quad \mathrm{M}_{2} \mathrm{M}_{3}^{\prime}=\varnothing, \quad \mathrm{M}_{3} \mathrm{M}_{4}^{\prime}=\varnothing, \quad \mathrm{M}_{4} \mathrm{M}_{5}^{\prime}=\varnothing, \quad \ldots, \quad \mathrm{M}_{\mathrm{n}-2} \mathrm{M}_{\mathrm{n}-1}{ }^{\prime}=\varnothing, \quad \mathrm{M}_{\mathrm{n}-1} \mathrm{M}_{\mathrm{n}}^{\prime}=\varnothing$

One may declare any of the $\left(\mathrm{p}_{1}\right),\left(\mathrm{p}_{2}\right),\left(\mathrm{p}_{3}\right)$ as being the "pattern Darii". Note that one can simultaneously use all the premises from all the premise choices: the one particular premise + two premise choices for the second premise + three premise choices for the third premise $+\ldots+(n-1)$ premise choices for the $(n-1)^{\text {th }}$ premise. The total number of premises would equal $n(n-1) / 2$. All these premise together might be declared as the "pattern Darii" - their "one subset LC" is the same as when one chooses just one "path through the premise choices": $M_{1} M_{2} \ldots M_{n-1} M_{n} \neq \varnothing$.

The induction on $n$ : Let suppose that all the subsets of $M_{1} M_{2} \neq \varnothing$ except the subset $M_{1} M_{2} M_{3} \ldots M_{n-1} M_{n}$ are emptied by any path through the choices for the $n-1$ premises. Once we add a new term, $M_{n+1}$, the "old subsets" receive the extra index $M_{n+1}$ thus $\mathrm{M}_{1} \mathrm{M}_{2} \ldots \mathrm{M}_{\mathrm{n}-1} \mathrm{M}_{\mathrm{n}} \mathrm{M}_{\mathrm{n}+1}$ remains definitely non-empty. And only its mirror subset $M_{1} M_{2} \ldots M_{n-1} M_{n} M_{n+1}$ ' will be definitely non-empty - among the mirrored subsets which received the $M_{n+1}$ ' as an extra index. Any of the $n$ possible choices for the $n^{\text {th }}$ premise of the Darii sorite, $M_{1} M_{n+1}=\varnothing, \quad M_{2} M_{n+1}=\varnothing \ldots M_{n-1} M_{n+1}=\varnothing$, $M_{n} M_{n+1}=\varnothing$, will empty the subset $M_{1} M_{2} \ldots M_{n-1} M_{n} M_{n+1}$ '. QED.

\section{$5 \quad$ There exist only three distinct syllogisms; they can be chosen to be Barbara, Darapti and Darii}

Once the structure of the Barbara, Darapti and Darii type sorites was made clear, one hopes that the argument that there is no real difference between the syllogisms Barbara, Celarent, Camestres, Bramantip, nor any difference between Darapti, Felapton, Fesapo, and no difference either between Disamis, Darii, Ferio, Bocardo, Baroco, will 
become clearer, too. In short, the argument is as follows: One may relabel the sets $\mathrm{M}_{1}, \mathrm{M}_{2}$, and $\mathrm{M}_{3}$ as $\mathrm{S}, \mathrm{P}, \mathrm{M}, \mathrm{S}^{\prime}, \mathrm{P}^{\prime}, \mathrm{M}^{\prime}$ in such a way that each syllogism of type Barbara corresponds to a "Barbara pattern of inclusions", $\mathrm{M}_{1} \subseteq \mathrm{M}_{2} \subseteq \mathrm{M}_{3}$, each syllogism of type Darapti corresponds to a "Darapti pattern of inclusions" $\mathrm{M}_{1} \subseteq \mathrm{M}_{2}$ and $\mathrm{M}_{1} \subseteq \mathrm{M}_{3}$, each syllogism of type Darii corresponds to a Darii "path of premise choices", $\mathrm{M}_{1} \mathrm{M}_{2} \neq \varnothing$ and $\mathrm{M}_{1} \mathrm{M}_{3}=\varnothing$, or, $\mathrm{M}_{1} \mathrm{M}_{2} \neq \varnothing$ and $\mathrm{M}_{2} \mathrm{M}_{3}{ }^{\prime}=\varnothing$. Then any difference among syllogisms of the same type is just a relabeling difference only. Firstly, we'll express all the valid categorical arguments and valid syllogisms of the same type by a single formula, which, by itself, will show that the only difference between syllogisms of the same type depends only on which set is denoted by either $\mathrm{S}$ or $\mathrm{S}^{\prime}$, which one is denoted by either $\mathrm{P}$ or $\mathrm{P}^{\prime}$, and which one is denoted by either $\mathrm{M}$ or $\mathrm{M}^{\prime}$ - the labeling changes do not influence the syllogisms' content. Instead of working only with premises formulable via only positive terms, one generalizes to premises containing negative terms, too. One way to get rid of the superfluous syllogistic figures is to notice that there are only six P-premises, (resp. Spremises), formulable via only positive terms; thus there are only 36 distinct PCPs under consideration in Classical Syllogistics, not 64. These six P-premises are: No M is $\mathrm{P}$ or $\mathrm{E}(\mathrm{M}, \mathrm{P})$, All $\mathrm{M}$ is $\mathrm{P}$ or $\mathrm{A}(\mathrm{M}, \mathrm{P})=\mathrm{E}\left(\mathrm{M}, \mathrm{P}^{\prime}\right), \mathrm{All} \mathrm{P}$ is $\mathrm{M}$ or $\mathrm{E}\left(\mathrm{M}^{\prime}, \mathrm{P}\right)$, Some $\mathrm{M}$ is $\mathrm{P}$ or $\mathrm{I}(\mathrm{M}, \mathrm{P})$, Some $\mathrm{M}$ is not $\mathrm{P}$ or $\mathrm{O}(\mathrm{M}, \mathrm{P})=\mathrm{I}\left(\mathrm{M}, \mathrm{P}^{\prime}\right)$, Some $\mathrm{P}$ is not $\mathrm{M}$ or $\mathrm{I}\left(\mathrm{M}^{\prime}, \mathrm{P}\right)$. One adds to these another two premises which cannot be written via using only positive terms: All $\mathrm{M}^{\prime}$ is $\mathrm{P}$ or $\mathrm{E}\left(\mathrm{M}^{\prime}, \mathrm{P}^{\prime}\right)$ and Some $\mathrm{M}^{\prime}$ is not $\mathrm{P}$ or $\mathrm{I}\left(\mathrm{M}^{\prime}, \mathrm{P}^{\prime}\right)$. Note that $\mathrm{E}(\mathrm{M}, \mathrm{P})$, $\mathrm{A}(\mathrm{M}, \mathrm{P})=\mathrm{E}\left(\mathrm{M}, \mathrm{P}^{\prime}\right), \mathrm{I}(\mathrm{M}, \mathrm{P})$, and $\mathrm{O}(\mathrm{M}, \mathrm{P})=\mathrm{I}\left(\mathrm{M}, \mathrm{P}^{\prime}\right)$, or $\mathrm{E}, \mathrm{A}, \mathrm{I}, \mathrm{O}$, make a square of opposition containing $M$ and $P$; and $E^{\prime}=E\left(M^{\prime}, P\right), A^{\prime}=A\left(M^{\prime}, P\right)=E\left(M^{\prime}, P^{\prime}\right), I^{\prime}=I\left(M^{\prime}, P\right)$ and $\mathrm{O}^{\prime}=\mathrm{O}\left(\mathrm{M}^{\prime}, \mathrm{P}\right)=\mathrm{I}\left(\mathrm{M}^{\prime}, \mathrm{P}^{\prime}\right)$, or $\mathrm{E}^{\prime}, \mathrm{A}^{\prime}, \mathrm{I}^{\prime}, \mathrm{O}^{\prime}$, make another square of opposition containing $\mathrm{M}^{\prime}$ and $\mathrm{P}$; together, they make a cube of opposition. In short, one can write now any universal, (resp. particular), P-premise as $\mathrm{E}\left(\mathrm{M}^{*}, \mathrm{P}^{*}\right)$, (resp. $\left.\mathrm{I}\left(\mathrm{M}^{*}, \mathrm{P}^{*}\right)\right)$, where $\mathrm{M}^{*} \in\{\mathrm{M}$, $\left.\mathrm{M}^{\prime}\right\}, \mathrm{P}^{*} \in\left\{\mathrm{P}, \mathrm{P}^{\prime}\right\}$. Similarly, the eight $\mathrm{S}$-premises can be written as $\mathrm{E}\left(\mathrm{M}^{*}, \mathrm{~S}^{*}\right)$ and $I\left(M^{*}, S^{*}\right)$ where $M^{*} \in\left\{M, M^{\prime}\right\}, S^{*} \in\left\{S, S^{\prime}\right\}$. The convention that the premise listed firstly contains the $\mathrm{P}$ term, allows writing a PCP via a shorthand notation which does not need to list the PCP's arguments: e.g., $A E^{\prime}$ means $A(M, P) E(M ', S)=A(M, P)$ $\mathrm{A}(\mathrm{S}, \mathrm{M})$, which are Barbara's premises. This convention partially matches Classical Syllogistics' convention that the first, (resp. second), vowel of a syllogism's name represents the statement of the $\mathrm{P}$, (resp. S), premise: thus one recognizes that EI are Ferio's premises - E(M,P)I(M,S), AI are Darii's premises - A(M,P)I(M,S), and IA are Disamis' premises - I(M,P)A(M,S), but one has to remember that Baroco's premises are in fact $\mathrm{E}^{\prime} \mathrm{I}^{\prime}=\mathrm{E}\left(\mathrm{M}^{\prime}, \mathrm{P}\right) \mathrm{I}\left(\mathrm{M}^{\prime}, \mathrm{S}\right)=\mathrm{A}(\mathrm{P}, \mathrm{M}) \mathrm{O}(\mathrm{S}, \mathrm{M})$, and that in Barbara, Celarent, Camestres and Bramantip one of their premises is not an A, but an E' premise. By choosing a premise from each cube of opposition one can build 64 distinct PCPs, out of which only 32 PCPs entail at least one LC and thus generate a valid categorical argument (VCA). Some of these valid categorical arguments (VCAs) are the valid syllogisms discussed in Section 2. The 32 PCPs which entail at least one LC comprise four groups of eight PCPs each: the Barbara, Darapti, Darii and Disamis types of valid categorical arguments (VCAs). The Darii and Disamis PCPs are transformed into each other via a relabeling $\mathrm{P} \leftrightarrow \mathrm{S}$ which does not change their logical content; for 
now, one considers them as distinct types even if both types follow the Darii's pattern. Their premises and LCs can be collected in one formula per each type, where, from now on, $M^{*} \in\left\{M, M^{\prime}\right\}, P^{*} \in\left\{P, P^{\prime}\right\}, S^{*} \in\left\{S, S^{\prime}\right\}$. Note that $M^{*}=M$ if $M^{*}=M^{\prime}$, etc. Each of the eight PCPs of type Barbara can be written as $\mathrm{E}\left(\mathrm{M}^{*}, \mathrm{P}^{*}\right) \mathrm{E}\left(\mathrm{M}^{*}, \mathrm{~S}^{*}\right)$, or $\mathrm{S}^{*} \subseteq \mathrm{M}^{*} \subseteq \mathrm{P}^{*}$ '. Such a PCP entails two, non-independent, but different, LCs - since these PCPs are in fact Barbara type sorites with just one middle term: $\mathrm{S}^{*} \subseteq \mathrm{M}^{*} \subseteq \mathrm{P}^{*}$, (or $\mathrm{P}^{*} \subseteq \mathrm{M}^{*} \subseteq \mathrm{S}^{* \prime}$ ). Instead of using $\mathrm{K}$-maps or 3-circle Venn diagrams to find the LCs of each type of PCPs, one can directly handle these PCPs using a tree like method, similar to Jevons' [12] method of decompositions into subsets, or to Lewis Carroll's [3] method of subscripts, and also similar to Carroll's [3] own method of trees. Reading the sorite in the Aristotelian way, i.e. starting with the $\mathrm{S}^{*}$ term of the PCP, one gets: $S^{*}=S^{*} M^{*}+S^{*} M^{* \prime}=S^{*} M^{*}=S^{*} M^{*} \mathrm{P}^{*}+S^{*} M^{*} \mathrm{P}^{* \prime}=S^{*} M^{*} \mathrm{P}^{*}$, where $S^{*} M^{*} \mathrm{P}^{*}:=$ $\mathrm{M}^{*} \cap \mathrm{S}^{*} \cap \mathrm{P}^{*}$, etc., and the + sign denotes union of (disjoint) sets. Reading the sorite in the Goclenian way, i.e. starting with the $\mathrm{P}^{*}$ term of the PCP, one gets the $2^{\text {nd }}$ LC: $\mathrm{P}^{*}=\mathrm{P}^{*} \mathrm{M}^{*}+\mathrm{P}^{*} \mathrm{M}^{*}=\mathrm{P}^{*} \mathrm{M}^{* \prime}=\mathrm{P}^{*} \mathrm{M}^{*} \mathrm{~S}^{*}+\mathrm{P}^{*} \mathrm{M}^{*} \mathrm{~S}^{* \prime}=\mathrm{P}^{*} \mathrm{M}^{*} \mathrm{~S}^{*}$. Note that based on the double inclusions $\mathrm{S}^{*} \subseteq \mathrm{M}^{*} \subseteq \mathrm{P}^{* \prime}$ and $\mathrm{P}^{*} \subseteq \mathrm{M}^{*} \subseteq \mathrm{S}^{* \prime}-$ inferred from the premises $\mathrm{E}\left(\mathrm{M}^{*}, \mathrm{P}^{*}\right) \mathrm{E}\left(\mathrm{M}^{*}, \mathrm{~S}^{*}\right)$ - each LC implies the other, i.e., only one LC is independent, but the two LCs pinpoint different subsets of U. Listing, after a column sign, and separated by semi-columns, all the possible LCs and LCs' formats, one may write:

(1) (Type Barbara) E(M*,P*)E( $\left.M^{*}, \mathrm{~S}^{*}\right): \mathrm{S}^{*}=\mathrm{S}^{*} \mathrm{M}^{*} \mathrm{P}^{*}, \mathrm{P}^{*}=\mathrm{P}^{*} \mathrm{M}^{*} \mathrm{~S}^{*} ; \mathrm{A}\left(\mathrm{S}^{*}, \mathrm{P}^{*}\right)$ $\left[=\mathrm{A}\left(\mathrm{P}^{*}, \mathrm{~S}^{* \prime}\right)=\mathrm{E}\left(\mathrm{S}^{*}, \mathrm{P}^{*}\right)\right]-$ after $\mathrm{M}^{*}$ is dropped, (classical syllogistics style!), the two LCs become identical and the number of all LCs of type Barbara reduces to only four; $\mathrm{I}\left(\mathrm{S}^{*}, \mathrm{P}^{* \prime}\right)$ - after ei on $\mathrm{S}^{*} ; \quad \mathrm{I}\left(\mathrm{P}^{*}, \mathrm{~S}^{*}\right) \quad-$ after ei on $\mathrm{P}^{*}$.

Note also that instead of using only formula $\left(\mathrm{b}_{0}\right) \mathrm{M}_{1} \subseteq \mathrm{M}_{2} \subseteq \mathrm{M}_{3} \subseteq \ldots \subseteq \mathrm{M}_{\mathrm{n}}$, to generate a unique Barbara sorite, one could have used the formulas $\left(\mathrm{b}_{0}{ }^{\prime}\right)$ $\mathrm{M}_{1}{ }^{*} \subseteq \mathrm{M}_{2}{ }^{*} \subseteq \mathrm{M}_{3}{ }^{*} \subseteq \ldots \subseteq \mathrm{M}_{\mathrm{n}}{ }^{*}$, where $\mathrm{M}_{\mathrm{i}}{ }^{*} \in\left\{\mathrm{M}_{\mathrm{i}}, \mathrm{M}_{\mathrm{i}}{ }^{\prime}\right\}, \mathrm{i}=1,2, \ldots, \mathrm{n}$, to generate $2^{\mathrm{n}}$ sorites. One can even apply $n$ ! permutations of the $n$ terms $M_{1}, M_{2}, M_{3}, \ldots, M_{n}$ and obtain $n ! 2^{n}$ Barbara type sorites generated by $\mathrm{n}$ terms. Classical Syllogistics gave a correct but partial answer when it refused to consider VCAs whose LCs are A(P,S) or O(P,S), since, via a permutation, (i.e., relabeling), those VCAs can be transformed into VCAs which have $\mathrm{A}(\mathrm{S}, \mathrm{P})$ or $\mathrm{O}(\mathrm{S}, \mathrm{P})$ as LCs. As with the eight 3-term syllogisms, one may ask: are these $2^{n}$, (or $n ! 2^{n}$ ), sorites really different - and deserving of different names - or are they just $2^{\mathrm{n}}$, (resp. $\mathrm{n} ! 2^{\mathrm{n}}$ ), relabelings of the same $\left(\mathrm{b}_{0}\right) \mathrm{M}_{1} \subseteq \mathrm{M}_{2} \subseteq \mathrm{M}_{3} \subseteq \ldots \subseteq \mathrm{M}_{\mathrm{n}}$ "pattern" Barbara sorite? I propose to study only the "pattern" Barbara syllogism and n-term sorite, and, via relabelings, to show that any other VCA from the same "family" reduces to the "pattern" Barbara syllogism or n-term sorite. It is even easier to find the LC of the eight Darapti type PCPs, $E\left(M^{*}, P^{*}\right) E\left(M^{*}, S^{*}\right)$. They entail just one universal LC: $M^{*}=M^{*} \mathrm{P}^{*}+\mathrm{M}^{*} \mathrm{P}^{* \prime}=\mathrm{M}^{*} \mathrm{P}^{*}=\mathrm{M}^{*} \mathrm{P}^{*} \mathrm{~S}^{*}+$ $\mathrm{M}^{*} \mathrm{P}^{*} \mathrm{~S}^{* \prime}=\mathrm{M}^{*} \mathrm{P}{ }^{*} \mathrm{~S}^{*}$, or $\mathrm{A}\left(\mathrm{M}^{*}, \mathrm{M}^{*} \mathrm{P}^{* '} \mathrm{~S}^{* \prime}\right)$ which reflects the inclusions $\mathrm{M}^{*} \subseteq \mathrm{P}^{* \prime}$ and $\mathrm{M}^{*} \subseteq \mathrm{S}^{* \prime}$ asserted by the premises. Thus, for the type Darapti PCPs, the middle term itself is "the subject" of the precise LC; it can be eliminated only via ei on M*. Listing, after a column sign, and separated by semi-columns, all the possible LCs, one may write the eight Darapti type VCAs as:

(2) (Darapti) $\mathrm{E}\left(\mathrm{M}^{*}, \mathrm{P}^{*}\right) \mathrm{E}\left(\mathrm{M}^{*}, \mathrm{~S}^{*}\right): \mathrm{M}^{*}=\mathrm{M}^{*} \mathrm{P}^{*} \mathrm{~S}^{* \prime}, \mathrm{A}\left(\mathrm{M}^{*}, \mathrm{M}^{*} \mathrm{P}^{*} \mathrm{~S}^{* \prime}\right) ; \mathrm{M}^{*} \mathrm{P}^{*} \mathrm{~S}^{*} \neq \varnothing$ if 
$\mathrm{M}^{*} \neq \varnothing$, or, $\mathrm{I}\left(\mathrm{S}^{*}, \mathrm{P}^{*}\right)$ if $\mathrm{M}^{*} \neq \varnothing$ and after $\mathrm{M}^{*}$ is eliminated. The non-ei VCA whose universal LC is All $\mathrm{M}^{*}$ is $\mathrm{M}^{*} \mathrm{P}^{*} \mathrm{~S}^{*}$, (resp. the ei VCA with the middle term $\mathrm{M}^{*}$ eliminated from the LC), will be called the non-ei Darapti, (resp. the ei Darapti). The nonei Darapti is not acknowledged by the Classical Syllogistics, because the middle term, $\mathrm{M}^{*}$, is the subject of the LC and thus cannot be simply dropped from the LC. (Imagine a Barbari without a Barbara, or a Bramantip without - wait a minute - Bramanta? Now imagine an ei Darapti, without the non-ei Darapti. Perfect - welcome to classical syllogistics!) In conclusion, the eight PCPs of type Darapti generate, before the middle term is dropped from the LCs, eight different non-ei VCAs. Only eight different ei VCAs remain after the middle term is dropped from the LCs and the non-ei LCs are discarded as per the Classical Syllogistics' approach. There are eight distinct PCPs of type Darii, $\mathrm{E}\left(\mathrm{M}^{*}, \mathrm{P}^{*}\right) \mathrm{I}\left(\mathrm{M}^{*}, \mathrm{~S}^{*}\right)$, and eight distinct PCPs of type Disamis, $\mathrm{I}\left(\mathrm{M}^{*}, \mathrm{P}^{*}\right)$ $E\left(M^{*}, S^{*}\right)$. The very short trees "revealing" the LCs are: $\emptyset \neq M^{*} S^{*}=M^{*} S^{*} P^{*}+$

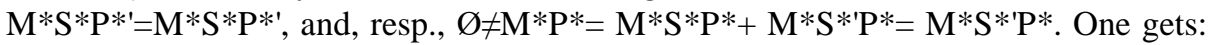

(3i) (Type Darii) $\quad \mathrm{E}\left(\mathrm{M}^{*}, \mathrm{P}^{*}\right) \mathrm{I}\left(\mathrm{M}^{*}, \mathrm{~S}^{*}\right): \mathrm{M}^{*} \mathrm{~S}^{*} \mathrm{P}^{*} \neq \varnothing ; \mathrm{I}\left(\mathrm{S}^{*}, \mathrm{P}^{*}\right)\left[=\mathrm{O}\left(\mathrm{S}^{*}, \mathrm{P}^{*}\right)\right]-$ after $\mathrm{M}^{*}$ is dropped from the LC. (Note: one writes the general PCP formulas using a minimal number of accents - at most one accent appears on the $M^{*}$ from the $S^{*}$ premise.)

(3ii) (Type Disamis) I(M*,P*)E( $\left.\mathrm{M}^{*}, \mathrm{~S}^{*}\right)$ : $\mathrm{M}^{*} \mathrm{P}^{*} \mathrm{~S}^{*} \neq \varnothing ; \mathrm{I}\left(\mathrm{P}^{*}, \mathrm{~S}^{*}\right)\left[=\mathrm{O}\left(\mathrm{P}^{*}, \mathrm{~S}^{*}\right)\right]$ - after $\mathrm{M}^{*}$ is dropped from the LC.

By making the substitutions $S^{*}=M_{1}, M^{*}=M_{2}, P^{*}=M_{3}$, where $M^{*} \in\left\{M, M^{\prime}\right\}$, $\mathrm{P}^{*} \in\left\{\mathrm{P}, \mathrm{P}^{\prime}\right\}, \mathrm{S}^{*} \in\left\{\mathrm{S}, \mathrm{S}^{\prime}\right\}$, all the eight Barbara type syllogisms become the "pattern" Barbara 3-term sorite, showing that all the eight Barbara type syllogisms have the same structure, the differences among them being accounted for by the elementary relabelings $\mathrm{p}:=\mathrm{P} \leftrightarrow \mathrm{P}^{\prime}$, (meaning $\left.\mathrm{p}(\mathrm{S}, \mathrm{P}, \mathrm{M})=\left(\mathrm{S}, \mathrm{P}^{\prime}, \mathrm{M}\right)\right), \mathrm{s}:=\mathrm{S} \leftrightarrow \mathrm{S}^{\prime}, \mathrm{m}:=\mathrm{M} \leftrightarrow \mathrm{M}^{\prime}$, and their compositions, ps, pm, sm, psm. Add to them a unit relabeling, e, and they form a commutative group, $G$, with eight elements. For example, $\operatorname{spm}(S, P, M)=\left(S^{\prime}, P^{\prime}, M^{\prime}\right)$, and $\mathrm{s}^{2}=\mathrm{p}^{2}=\mathrm{m}^{2}=$ e. Since denoting a term, e.g., by either $\mathrm{S}$ or by $\mathrm{S}^{\prime}$ does not a logical difference make, it results that the group $\mathrm{G}$ does not act on logical content, and thus there is no logical difference between Barbara, Celarent, Camestres and the Bramantip's premises - to which one adds their precise two universal LCs, $\mathrm{P}=\mathrm{SPM}:=\mathrm{S} \cap \mathrm{P} \cap \mathrm{M}$ and $S^{\prime}=S^{\prime} P^{\prime} M '$. Indeed, relabeling the $S, P, M$ terms from Barbara as $S^{\prime}, P^{\prime}, M^{\prime}$, i.e., by applying the spm relabeling, Barbara's $\mathrm{PCP}$, in the new relabeling, becomes Bramantip's PCP: $\mathrm{A}\left(\mathrm{M}^{\prime}, \mathrm{P}^{\prime}\right) \mathrm{A}\left(\mathrm{S}^{\prime}, \mathrm{M}^{\prime}\right)=\mathrm{A}(\mathrm{P}, \mathrm{M}) \mathrm{A}(\mathrm{M}, \mathrm{S})$; Barbara's two LCs, in the new relabeling become $S^{\prime}=S^{\prime} P^{\prime} M$ ' and $\mathrm{P}=\mathrm{SPM}$, i.e., they are Bramantip's universal LCs, too. The set of eight valid categorical arguments (VCAs) of type Barbara is left invariant under the action of the relabeling group G. By removing the Classical Syllogistics' restrictions - only PCPs formulable via positive terms are acceptable, only the statements $\mathrm{A}(\mathrm{S}, \mathrm{P}), \mathrm{E}(\mathrm{S}, \mathrm{P}), \mathrm{I}(\mathrm{S}, \mathrm{P}), \mathrm{O}(\mathrm{S}, \mathrm{P})$ are the acceptable LCs (equivalent to the condition that $\mathrm{P}$ has to be the predicate of the conclusion, i.e., $\mathrm{LC}$ ), one can more clearly grasp that the only difference between the eight Barbara type syllogisms (or VCAs) is a group $\mathrm{G}$ of relabelings, which do not change the logical content of the relabeled syllogisms. To the "pattern" Darapti, $\mathrm{M}_{1} \mathrm{M}_{2}^{\prime}=\varnothing, \mathrm{M}_{1} \mathrm{M}_{3}^{\prime}=\varnothing$, correspond the eight Darapti type syllogisms encompassing Darapti, Felapton, etc., written as $\mathrm{E}\left(\mathrm{M}^{*}, \mathrm{P}^{*}\right)$ $E\left(M^{*}, S^{*}\right): M^{*}=M^{*} S^{*} P^{* \prime}$, where the precise LC is listed after the column sign. If ei on $\mathbf{M}^{*}$ is imposed, by requiring $\mathrm{M}^{*} \neq \varnothing$, and then the term $\mathrm{M}^{*}$ is dropped, the precise 
LC might become, depending on the $\mathrm{S}^{*}$ and $\mathrm{P}^{*}$ values, an accepted LC: I( $\left.\mathrm{S}^{*}, \mathrm{P}^{* \prime}\right)$. The set of eight Darapti type syllogisms is invariant under G. By making the correspondences $M^{*}=M_{1}, P^{* \prime}=M_{2}, S^{*}=M_{3}$, where $M^{*} \in\left\{M, M^{\prime}\right\}, P^{*} \in\left\{P, P^{\prime}\right\}, S^{*} \in\{S$, $\mathrm{S}^{\prime}$ \}, all the eight Darapti type syllogisms become the "pattern" Darapti 3-term sorite, showing that all the eight Darapti type syllogisms have the same structure, all the differences among them being accounted for by the relabeling group $\mathrm{G}$. To one of the "pattern" Darii, $\mathrm{M}_{1} \mathrm{M}_{2} \neq \varnothing, \mathrm{M}_{1} \mathrm{M}_{3}=\varnothing$, (see formula $\left(\mathrm{p}_{1}\right)$ in Section 4), correspond the eight Darii type syllogisms encompassing Darii, Ferio, Baroco, etc., written as $\mathrm{E}\left(\mathrm{M}^{*}, \mathrm{P}^{*}\right) \mathrm{I}\left(\mathrm{M}^{*}, \mathrm{~S}^{*}\right): \mathrm{S}^{*} \mathrm{M}^{*} \mathrm{P}^{*} \neq \varnothing$, where the precise $\mathrm{LC}$ is listed after the column sign. By making the correspondences $M^{*}=M_{1}, S^{*}=M_{2}, P^{*}=M_{3}$, where $M^{*} \in\{M$,

$\left.\mathrm{M}^{\prime}\right\}, \mathrm{P}^{*} \in\left\{\mathrm{P}, \mathrm{P}^{\prime}\right\}, \mathrm{S}^{*} \in\left\{\mathrm{S}, \mathrm{S}^{\prime}\right\}$, all the eight Darii type syllogisms become the "pattern" Darii 3-term sorite, showing that all the eight Darii type syllogisms have the same structure, the differences among them being accounted for by the relabeling group $\mathrm{G}$. To the same "pattern" Darii, $\mathrm{M}_{1} \mathrm{M}_{2} \neq \varnothing, \mathrm{M}_{1} \mathrm{M}_{3}^{\prime}=\varnothing$, (see formula ( $\mathrm{p}_{1}$ ) in Section 4), also correspond the eight Disamis type syllogisms, encompassing Disamis, Bocardo, etc., written as $\mathrm{I}\left(\mathrm{M}^{*}, \mathrm{P}^{*}\right) \mathrm{E}\left(\mathrm{M}^{*}, \mathrm{~S}^{*}\right): \mathrm{S}^{*} \mathrm{M}^{*} \mathrm{P}^{*} \neq \varnothing$, where the precise $\mathrm{LC}$ is listed after the column sign. By making the correspondences $\mathrm{M}^{*}=\mathrm{M}_{1}, \mathrm{P}^{*}=\mathrm{M}_{2}, \mathrm{~S}^{*}=\mathrm{M}_{3}$, (which, compared to the Darapti correspondences, also includes the $\mathrm{S} \leftrightarrow \mathrm{P}$ relabeling), and where $M^{*} \in\left\{M, M^{\prime}\right\}, P^{*} \in\left\{P, P^{\prime}\right\}, S^{*} \in\left\{S, S^{\prime}\right\}$, all the eight Disamis type syllogisms become the "pattern" Darii 3-term sorite, showing that all the eight Disamis type syllogisms have the same structure, the differences among them being accounted for by the relabeling group G. Equivalently, one may have observed that any Disamis syllogism becomes a Darii syllogism and vice-versa, via the relabeling $\mathrm{S} \leftrightarrow \mathrm{P}$, which is devoid of any logical content.

\section{The detailed action of the relabeling group $G$ on the 64 distinct pairs of categorical premises}

The 64 distinct PCPs obtained by pairing each one of the eight distinct P-premises with each one of the eight distinct S-premises, split into eight groups of eight PCPs per group: the four groups of (1)-Barbara, (2)-Darapti, (3i)-Darii and (3ii)-Disamis type PCPs, plus there are two other PCP types - split into four PCP subtypes - which do not entail any LC: (4i) I(M*,P*) I(M*, $\left.\mathrm{S}^{*}\right)$ and (4ii) $\mathrm{I}\left(\mathrm{M}^{*}, \mathrm{P}^{*}\right) \mathrm{I}\left(\mathrm{M}^{*}, \mathrm{~S}^{*}\right)$ - each subtype contains eight PCPs made of two particular premises, and, (5i) $\mathrm{E}\left(\mathrm{M}^{*}, \mathrm{P}^{*}\right) \mathrm{I}\left(\mathrm{M}^{*}, \mathrm{~S}^{*}\right)$ and $(5 \mathrm{ii}) \mathrm{I}\left(\mathrm{M}^{*}, \mathrm{P}^{*}\right) \mathrm{E}\left(\mathrm{M}^{*}, \mathrm{~S}^{*}\right)$ - each subtype contains eight PCPs made of one universal and one particular premises, one "acting on" $\mathrm{M}$ and the other on $M^{\prime}$, where $M^{*} \in\left\{M, M^{\prime}\right\}, P^{*} \in\left\{P, P^{\prime}\right\}, S^{*} \in\left\{S, S^{\prime}\right\}$. Since each of the PCP sets (1), (2), (3i), (3ii), (4i), (4ii), (5i), (5ii), is expressed by a formula depending only on $\mathrm{S}^{*}$, $\mathrm{M}^{*}$ and $\mathrm{P}^{*}$, it results that each such set is left invariant by the action of the group $\mathrm{G}$. For example, on the Barbara type VCAs, $m($ Celarent $)=$ Camestres, $\mathrm{p}($ Celarent $)=$ Barbara, $\mathrm{pm}($ Camestres $)=\mathrm{mp}($ Camestres $)=$ Barbara. But one can define for the group G a "super-action" on the set of eight subsets, (containing eight PCPs 
each), $A_{i}, i=1,2, \ldots, 8$ obtained, from the Table 1 , as follows. Firstly denote $1:=(\mathrm{S}, \mathrm{M}, \mathrm{P}), \quad 2:=\left(\mathrm{S}^{\prime}, \mathrm{M}, \mathrm{P}\right), \quad 3:=\left(\mathrm{S}, \mathrm{M}, \mathrm{P}^{\prime}\right), \quad 4:=\left(\mathrm{S}^{\prime}, \mathrm{M}, \mathrm{P}^{\prime}\right), \quad 5:=\left(\mathrm{S}, \mathrm{M}^{\prime}, \mathrm{P}\right), \quad 6:=\left(\mathrm{S}^{\prime}, \mathrm{M}^{\prime}, \mathrm{P}\right)$, $7:=\left(S, M^{\prime}, P^{\prime}\right), 8:=\left(S^{\prime}, M^{\prime}, P^{\prime}\right)$. Note the action of $G$ on the set $\{1,2, \ldots, 8\}: s(i)=i+1$, for $\mathrm{i}=1,3,5,7$, and, (since $\mathrm{s}^{2}=e$ ), $\mathrm{s}(\mathrm{i})=\mathrm{i}-1$, for $\mathrm{i}=2,4,6,8$; $\mathrm{p}(\mathrm{i})=\mathrm{i}+2$, for $\mathrm{i}=1,2,5,6$, and, $p(i)=\mathrm{i}-$ 2 , for $\mathrm{i}=3,4,7,8 ; \mathrm{m}(\mathrm{i})=\mathrm{i}+4$, for $\mathrm{m}=1,2,3,4$, and, $\mathrm{m}(\mathrm{i})=\mathrm{i}-4$, for $\mathrm{m}=5,6,7,8$. Denote by $\mathrm{A}_{1}$, the set of eight PCPs, (and VCAs), appearing in Table 1 when $\left(\mathrm{S}^{*}, \mathrm{M}^{*}, \mathrm{P}^{*}\right)$ $=(S, M, P)=: 1 ;$ similarly define the sets $A_{i}, i=2, \ldots, 8$. One can see that the action of $G$ on $\left\{A_{i}, i=1,2, \ldots, 8\right\}$ mimics the action of $G$ on the above set of triplets $\{1, \ldots, 8\}$ : $\mathrm{s}\left(\mathrm{A}_{\mathrm{i}}\right)=\mathrm{A}_{\mathrm{i}+1}$, for $\mathrm{i}=1,3,5,7, \mathrm{~s}\left(\mathrm{~A}_{\mathrm{i}}\right)=\mathrm{A}_{\mathrm{i}-1}$, for $\mathrm{i}=2,4,6,8$, etc. Also $\left\{\mathrm{G}\left(\mathrm{A}_{1}\right)\right\}=\ldots=\left\{\mathrm{G}\left(\mathrm{A}_{8}\right)\right\}=\{$ $\left.\mathrm{A}_{1}, \mathrm{~A}_{2}, \mathrm{~A}_{3}, \ldots, \mathrm{A}_{8}\right\}=\{$ All the 64 PCPs and their respective LCs if any $\}$.

Table 1. The 64 elements PCP matrix reduces to a two by four matrix of the PCP types and their logical consequences (LCs) if any. The set $A_{1}$, (resp. $A_{2}$ ), is made of the 8 matrix elements below when $\left(S^{*}, P^{*}, M^{*}\right)$ take the values $(S, P, M)$, (resp. $\left.\left(S^{\prime}, M, P\right)\right)$. Similarly defined: $A_{3}, ., A_{8}$.

\begin{tabular}{|c|c|c|c|c|}
\hline & $\mathrm{E}(\mathrm{M} *, \mathrm{~S} *)$ & $\mathrm{I}\left(\mathrm{M}^{*}, \mathrm{~S}^{*}\right)$ & $\mathrm{E}\left(\mathrm{M}^{* \prime}, \mathrm{S}^{*}\right)$ & $\mathrm{I}\left(\mathrm{M}^{* \prime}, \mathrm{S} *\right)$ \\
\hline $\begin{array}{l}\mathrm{E}\left(\mathrm{M}^{*},\right. \\
\left.\mathrm{P}^{*}\right)\end{array}$ & $\begin{array}{l}\mathrm{E}\left(\mathrm{M}^{*}, \mathrm{P}^{*}\right) \mathrm{E}\left(\mathrm{M}^{*}, \mathrm{~S}^{*}\right): \\
\mathrm{M}^{*}=\mathrm{M}^{*} \mathrm{~S}^{* \prime} \mathrm{P}^{* \prime} \\
\text { Darapti }\end{array}$ & $\begin{array}{l}\mathrm{E}\left(\mathrm{M}^{*}, \mathrm{P}^{*}\right) \mathrm{I}\left(\mathrm{M}^{*}, \mathrm{~S}^{*}\right): \\
\mathrm{M}^{*} \mathrm{~S}^{*} \mathrm{P}^{*} \neq \varnothing \\
\text { Darii }\end{array}$ & $\begin{array}{l}\mathrm{E}\left(\mathrm{M}^{*}, \mathrm{P}^{*}\right) \mathrm{E}\left(\mathrm{M}^{* \prime}, \mathrm{S}^{*}\right) \\
\mathrm{S}^{*}=\mathrm{M}^{*} \mathrm{~S}^{*} \mathrm{P}^{* \prime} \\
\mathrm{P}^{*}=\mathrm{M}^{* \prime} \mathrm{S}^{*} \mathrm{P} \mathrm{P}^{*} \text { Barbara }\end{array}$ & $\begin{array}{l}\mathrm{E}\left(\mathrm{M}^{*}, \mathrm{P}^{*}\right) \mathrm{I}\left(\mathrm{M}^{* 1},\right. \\
\left.\mathrm{S}^{*}\right)\end{array}$ \\
\hline $\begin{array}{l}\mathrm{I}\left(\mathrm{M}^{*}\right. \\
\left.\mathrm{P}^{*}\right)\end{array}$ & $\begin{array}{l}\mathrm{I}\left(\mathrm{M}^{*}, \mathrm{P}^{*}\right) \mathrm{E}\left(\mathrm{M}^{*}, \mathrm{~S}^{*}\right): \\
\mathrm{M}^{*} \mathrm{~S}^{*} \mathrm{P} \mathrm{P}^{* \prime} \neq \varnothing \\
\text { Disamis }\end{array}$ & $\begin{array}{c}\mathrm{I}\left(\mathrm{M}^{*}, \mathrm{P}^{*}\right) \mathrm{I}\left(\mathrm{M}^{*}, \mathrm{~S}^{*}\right) \\
(4 \mathrm{i})\end{array}$ & $\begin{array}{c}\mathrm{I}\left(\mathrm{M}^{*}, \mathrm{P}^{*}\right) \mathrm{E}\left(\mathrm{M}^{* \prime}, \mathrm{S}^{*}\right) \\
(5 \mathrm{ii})\end{array}$ & $\begin{array}{l}\mathrm{I}\left(\mathrm{M}^{*}, \mathrm{P}^{*}\right) \mathrm{I}\left(\mathrm{M}^{* \prime},\right. \\
\left.\mathrm{S}^{*}\right) \\
\quad(4 \mathrm{ii})\end{array}$ \\
\hline
\end{tabular}

\section{Conclusions}

One saw that, based on set inclusions and set intersections, only three distinct patterns of valid syllogisms or valid categorical arguments (VCAs) do exist - they represent the $n=3$ case of the $n$ terms biliteral sorites of the Barbara, Darapti and Darii patterns. To argue that all the 32 valid categorical arguments can be reduced to only Barbara, Darapti and Darii, one could have worked only with the relabeling group $\mathrm{G}$ with $2^{3}$ elements, and the relabeling $\mathrm{S} \leftrightarrow \mathrm{P}$, (Quine [13] calls it relettering), without ever mentioning the "pattern" Barbara, Darapti and Darii n-term sorites. But by agreeing that treating the $2^{\mathrm{n}}$, ( or $n ! 2^{\mathrm{n}}$ ), relabelings of each of the three pattern sorites as being distinct sorites would be a huge waste of time, one gets the idea that, (nowadays, after more than 2300 years since Aristotle invented the syllogisms), treating with unchanging awe the $2^{3}$ relabelings of each set of the valid categorical arguments of types Barbara, Darapti, Darii and Disamis, is not such a great idea, either. Boole's [2] and especially Carroll's [3], "three valid categorical argument (VCA) pattern approach" so clearly displays the structure of any VCA, that, I think, after millennia, one should take away the center stage from the valid syllogisms' moods and figures, (whose awkwardness was also described by Venn [14]), and accept that there are only three distinct syllogisms, Barbara, Darapti and Darii, which may be rewritten as any other valid categorical argument of their respective patterns. 


\section{References}

1. Boole, George: An Investigation of the Laws of Thought on Which are Founded the Mathematical Theories of Logic and Probabilities. Macmillan, London (1854). Or: Dover Publications, New York (1958).

2. Boole, George: The mathematical analysis of logic, being an essay towards a calculus of deductive reasoning, pp. 34-38. Macmillan, Barclay, \& Macmillan, Cambridge (1847).

3. Carroll, Lewis: Symbolic Logic, pp. 250, 240. Reprinted. Part I Elementary, 1896. Fifth Edition. Part II, Advanced, never previously published. Edited, with annotations and an introduction, by William Warren Bartley, III. Reprint edition. Clarkson Potter, New York (1986).

4. Burris, Stanley: George Boole. The online Stanford Encyclopedia of Philosophy, https://plato.stanford.edu/entries/boole.

5. Copi, I. M., Cohen, C., McMahon, K: Introduction to Logic. $14^{\text {th }}$ edition. Pearson Education Limited, Harlow, England (2014).

6. Hurley, P. J.: A Concise Introduction to Logic. 12th editionn. Cengage Learning, Stamford, CT (2015).

7. Marquand, Allan: On logical diagrams for $n$ terms. Philosophical Magazine (12), 266-270 (1881). DOI: 10.1080/14786448108627104.

8. Venn, John: On the Diagrammatic and Mechanical Representation of Propositions and Reasonings. The London, Edinburgh, and Dublin Philosophical Magazine and Journal of Science. Series 5, Vol 9 (No. 59), 1-18 (1880). DOI: 10.1080/14786448008626877.

9. Veitch, Edward, W.: A chart method for simplifying truth functions. Proceedings of the Association for Computing Machinery 127-133 (1952). ACM, Pittsburgh. DOI: 10.1145/609784.609801.

10. Karnaugh, Maurice: The map method for synthesis of combinational logic circuits. Transactions of the Institute of Electrical Engineers, Part 1. (72), 593-599 (1953). DOI: $10.1109 /$ TCE.1953.6371932.

11. Abdalla, Yasser: Introducing the Yasser-map as an improvement of the Karnaugh-map for solving logical problems. In: Proceedings of the First IEEE ICECCT. IEEE, pp. 1-5 (2015). DOI: 10.1109/ICECCT.2015.7226152.

12. Jevons, W. Stanley: The Substitution Of Similars, The True Principle Of Reasoning, Derived From A Modification Of Aristotle 's Dictum. Macmillan And Co., London (1869). Reprint Edition: Wentworth Press (2019).

13. Quine, Willard Van Orman: Methods of Logic, p. 106. $4^{\text {th }}$ edition. Harvard University Press, Cambridge MA (1982).

14. Venn, John: Symbolic Logic. $2^{\text {nd }}$ edition, Macmillan, London (1894). Reprint edition: AMS Chelsea Publishing, Providence RI, pp. 402-406. (2006). 